УДК 61(09)(470.621)

https://doi.org/10.47370/2078-1024-2020-12-4-51-59

\title{
Тхагапсова Г.Г.
}

\section{РАЗВИТИЕ МЕДИЦИНЫ И ЗДРАВООХРАНЕНИЯ В АДЫГЕЕ В ПОСЛЕВОЕННЫЙ ПЕРИОД (1946-1985 ГГ.)}

\author{
Тхагапсова Галина Григорьевна, \\ кандидат исторических наук, ведущий научный сотрудник \\ ГБУ РА «Адыгейский'республиканский институт гуманитариых исследо- \\ ваний им. T.М. Кераиева», Майкоп, Россия, \\ e-mail: galinatxa@mail.ru, \\ тел.: +7.(903) 4653338
}

\section{Аннотация}

Рассмотрено развитие здравоохранения в Адыгее в годы послевоенных пятилеток. Несмотря на сложности восстановительного периода, государство считало одной из приоритетных задач охрану здоровья населения. Необходимо было в кротчайшие сроки не только восстановить, но и повысить качество диагностической и лечебной помощи. В статье на основе анализа архивных материалов рассмотрена реализация указанных задач Адыгоблздравотделом. Продемонстрированы высокие темпы строительства и расширения сети лечебных учреждений в послевоенные годы в Адыгее.

Большое внимание уделялось организации специализированной помощи. Достижения медицинской науки и техники позволили проводить более глубокие обследования больных и применять новые методы лечения. Для врачей становится обязательным планирование прохождения специализации и повышения профессионального уровня. Расширяется сеть лечебных учреждений, активно вводятся в строй новые: областная больница, детская, инфекционная, а также отделения гинекологическое, нейрохирургическое, травматологическое и др. Сделан вывод о том, что, несмотря на экономические сложности, советское государство уделяло большое внимание охране здоровья народа, считая ее одной из важнейших социальных функций. Такая постановка проблемы на государственном уровне и высокая ответственность региональных властей при использовании государственных ассигнований позволили построить за годы советской власти эффективную систему медицинской службы в Адыгее.

Ключевые слова: Адыгейская автономная область, медицина, здравоохранение, послевоенные годы, лечебные учреждения.

Для цитирования: Тхагапсова Г.Г. Развитие медицины и здравоохранения в Адыгее в послевоенный период (1946-1985 г2.) // Вестник Майкопского государствениого технологического 'университета. 2020. Том 12, № 4. C. 51-59. https:/doi. org/10.47370/2078-1024-2020-12-4-51-59. 
Tkhagapsova G.G.

DEVELOPMENT OF MEDICINE AND HEALTH CARE IN ADYGEA IN THE POST-WAR PERIOD (1946-1985)

\author{
Tkhagapsova Galina Grigorievna, \\ Candidate of History, a leading researcher \\ SBI RA «The Adygh Republican Institute of Humanitarian Research named after \\ TM, Kerashev», Maykop, Russia, \\ e-mail: galinatxa@mail.ru, \\ tel.: +7.(903) 4653338
}

Annotation

The development of health care in Adygea during the post-war five-year plans is considered. Despite the difficulties of the recovery period, the state considered one of the priority tasks to protect the health of the population. It was necessary not only to restore, but also to improve the quality of diagnostic and medical care in the shortest possible time. In the article the implementation of these tasks by the Adygoblzdrav department has been considered on the basis of the analysis of archival materials. The high rates of construction and expansion of the network of medical institutions in the post-war years in Adygea were demonstrated. Much attention was paid to the organization of specialized assistance. Advances in medical science and technology made it possible to conduct deeper examinations of patients and apply new methods of treatment. It became mandatory for doctors to plan for specialization and professional development. The network of medical institutions was expanding, new ones were being actively put into operation: the regional hospital, children's, infectious diseases, as well as gynecological, neurosurgical, traumatological, etc. departments. It was concluded that, despite the economic difficulties, the Soviet state paid great attention to protecting the people's health, considering it one of the most important social functions. This formulation of the problem at the state level and the high responsibility of the regional authorities in the use of state allocations made it possible to build an effective system of medical service in Adygea during the Soviet power era.

Keywords: the Adygh Autonomous Region, medicine, health care, post-war years, medical institutions.

For citation: Tkhagapsova G.G. Development of medicine and health care in Adygea in theipostwarperiod.(1946-1985)//VestnikMajkopskogo Gosudarstvennogo Tehnologiceskogo Universiteta. 2020. Vol. 12, No4.P. 51-59. https:/doi.org/10.47370/2078-1024-2020-12-4-51-59.

Послевоенный период - один из сложнейших этапов истории России XX в. Стране, победившей немецкий фашизм, необходимо было совершить еще один подвиг - трудовой, восстановить разрушенное хозяйство. Для Адыгейской автономной области, находившейся под оккупацией с августа 1942 г. по февраль 1943 г., восстановительные работы стоили неимоверного напряжения физических и психических сил. Одним из значительных событий после оккупационного периода стало решение Адыгейского облисполкома от 6 апреля 1943 г. о формировании на территории г. Майкопа эвакогоспиталей НКЗ на 800 коек. Вслед за этим событием в течение четырех месяцев большая часть учреждений здравоохранения была восстановлена и приступила к работе. Врачебный штат послевоенной больницы значительно увеличился и изменился. В июле 1946 г. главный врач больницы Н.И. Клюев переводится на должность заведующего отделением, а 
на его место назначается тов. М.Д. Дмитриенко В коллектив вернулись ветераны городской службы здравоохранения, известные врачи. Заведующим хирургическим отделением стал А.Б. Апель, имеющий ученое звание доцента, гинекологическим отделением - кандидат медицинских наук М.П. Солодкий Родильное отделение возглавила заслуженный врач РСФСР Л.К. Венславская, заведующим инфекционным отделением назначен Ф.И. Иванюта. Коллектив пополнился и молодыми врачами-ординаторами: терапевты И.В. Ерохина, О.В. Сеньковская, хирурги С.Н. Залиева, А.И. Чухо, Е.Л. Нестерова, педиатр А.А. Быкова [1].

Послевоенный период для медицинской отрасли начался с ряда организационных реформ. В соответствии с Законом СССР от 15 марта 1946 г. «О преобразовании СНК СССР в Совет Министров СССР и Советов Народных Комиссаров союзных и автономных республик в Coветы Министров союзных и автономных республик» Народный комиссариат здравоохранения СССР был преобразован в Министерство здравоохранения СССР (М3 СССР), Народный комиссар здравоохранения - в Министра здравоохранения, Наркомздравы союзных и автономных республик - в Министерства здравоохранения союзных и автономных республик [2]. В целях повышения качества медицинского обслуживания населения МЗ СССР приступило к проведению реформы, стержнем которой являлось объединение больниц и поликлиник. Решение об этом было принято в мае 1947 г. на состоявшемся в Москве совещании актива работников здравоохранения после доклада Е.И. Смирнова, назначенного министром здравоохранения СССР в феврале этого же года.

На местах активно началась реализация нового постановления, в связи с чем в феврале 1948 г., руководствуясь новым решение М3 СССР, Адыгейский обдздравотдел проводит следующую реорганизацию: областная больница переводится на бюджет горздрава и становится городской. Формируется больнично-поликлиническое объединение, главным врачом назначается доктор Алексеева. Новый метод организации обслуживания больных имел как положительные, так и отрицательные стороны. Положительные: врачи в новой системе обслуживания имели больше возможностей для повышения своего профессионального уровня, а также могли продолжать наблюдение больного в поликлинике после стационара. Отрицательные моменты: поликлиники были расположены на значительном расстоянии от больницы, и длительные переходы при отсутствии транспорта занимали много времени, что приводило к скоплению очередей в поликлиниках и к нареканиям и недовольству больных, а также к нарушению контроля над трудовой дисциплиной [3].

Важную роль в жизни медицинской общественности Майкопа послевоенных лет имела работа научного общества врачей. Созданное еще в 1924 г. по инициативе заслуженного врача РСФСР Н.И. Клюева и при поддержке докторовбратьев В.Ф. Соловьева и А.Ф. Соловьева, а также врачей П.В. Гутовского, М. Шевцова, Л.Б. Шварца общество стало центром интеллектуального общения врачей. Если в 1924 г. в него входило 29 врачей, то в 60-е годы - 120 врачей. С 1927 по 1944 гг. возглавлял его видный хирург, доцент А.Б. Апель. В послевоенные годы при отсутствии источников информации общество было центром обмена опытом, мнениями, идеями. На заседаниях зачитывались доклады, разбирались сложные случаи из практики. Для молодых врачей это была школа повышения квалификации, углубления и расширения медицинских знаний.

В конце 50-х годов одной из проблем здравоохранения Адыгеи становится организация специализированной помощи. Развитие специализированной помощи было велением времени и необходимым условием оказания квалифицированной помощи больным. Достижения медицинской науки и техники позволили 
проводить более глубокие обследования и применять новые методы лечения. Теперь обязательным в планировании работы врачей и службы в целом является специализация и повышение профессионального уровня. Врачи активно поддержали и включились в эту работу. Прошли специализацию по урологии хирурги И.И. Баланов, С.Н. Залиева, по гинекологии Г.В. Хачикова, В.М. Лосев по стоматологии В.П. Смолин. Врачи В.Д. Коваленко, В.Н. Грек, Л.М. Козлова прошли специализацию по отоларингологии, врачи Г.И. Коваленко, Л.В. Кустова, Е.С. Чертова, А.И. Катькалова изъявили желание специализироваться по глазной хирургии [4].

В 1960 г. в медицинской службе города произошло важное организационное мероприятие. Облисполком принял решение о создании на базе расформированного ортопедического госпиталя областную больницу на 150 коек с отделениями терапевтическим, гинекологическим, хирургическим, в составе которых предусматривались койки для лечения ушных и глазных болезней. Больница должна была обслуживать сельское население области, в связи с чем ей передавалась станция санитарной авиации. Возглавил новую структуру молодой и энергичный врач, талантливый руководитель Нурбий Цукович Хагундоков. В дальнейшем становление, рост, расширение коечной сети, подбор кадров и формирование высокопрофессионального коллектива проходило под его руководством. Областная больница стала его детищем [5].

Развитие здравоохранения в Адыгее в 1960-е годы шло поступательно, показывая высокую организованность и эффективность, что подтвердили результаты проверки работы Облздравотдела солидной и авторитетной комиссией в составе представителя Минздрава, главного терапевта Крайздравотдела и представителей Крайисполкома. На совещании городских врачей, где комиссия докладывала о результатах проверки, была дана высокая оценка работе лечебных учреждений города. Комиссия отметила стройную, четкую организацию медобслуживания, добросовестную работу участковых медсестер, хорошую организацию диспансеризации, высокую квалификацию, трудолюбие, трудоспособность, самоотдачу медицинских кадров. Действительно, здравоохранение области могло гордиться известными, высокопрофессиональными и всеми уважаемыми врачами как М.П. Солодкий, Л.К. Венславская, В.Н. Зюзина, М.И. Бек, Ю.А. Асмус, А.Г. Киншина, И.В. Ерохина, В.В. Цыпленков, В.И. Апарина, В.П. Смолин, С.Н. Залиева и др. [6].

В 70-е годы главным направлением развития здравоохранения области является расширение коечной мошности и строительство новых типовых объектов. В этот период активного капитального строительства и расширения сети лечебных учреждений областной отдел здравоохранения возглавлял Шишхов Довлетчерий Махмудович, городской с 1967 года - Чиназиров Пуш Мухтарович [7]. Уже в июне 1961 г. принимаются меры по увеличению пропускной способности поликлинических учреждений за счет строительства нового и использования зданий административных учреждений. Построено здание женской консультации, начаты работы по строительству детской больницы на 100 коек. В конце 1964 г. введен в строй хирургический корпус городской больницы. Перевод в новое здание хирургического отделения позволил расширить коечную мощность родильного отделения на 106 коек. В новом лечебном корпусе областной больницы развернуты: хирургическое, гинекологическое, детское и приемное отделения.

Остро стоял вопрос и об организации психиатрической помощи больным, необходимым было создание психоневрологического диспансера. Решение этой проблемы отстаивал врач-психиатр Куваев Аскарбий Юсуфович - один из первых организаторов психиатрической помощи в Адыгее. И наконец, приказом № 162 Облздравотдела от 25.12.1966 г. 
областной психоневрологический кабинет, в котором уже работали 5 врачей и 8 средних медицинских работника, был преобразован в психоневрологический диспансер, что позволило значительно улучшить помощь этой категории больных, хотя по-прежнему остро стоял вопрос о стационаре [8]. Необходимо было также расширять помощь онкобольным. Организованного еще в 1953 году онкологического пункта, возглавляемого заслуженным врачом РСФСР Лесюис М.А., явно было недостаточно. С 5 января 1966 г. организуется онкологический диспансер на базе городской больницы, а с 1 августа 1967 г. отделение на 45 коек, в этом же году начинается строительство диспансеров по типовому проекту со стационаром на 90 коек, пансионатом на 80 коек и радиологическим отделением на 12 коек.

Облздравотделом были приняты меры и по организации нейрохирургической помощи. В сентябре 1966 г. в хирургическом отделении областной больницы выделено 10 нейрохирургических коек. Поставлен вопрос о целесообразности организации нейрохирургического отделения на 25-30 коек. Впоследствии его возглавит первый нейрохирург Адыгеи Гвашев Инвербий Пшихизович. Он закончил клиническую ординатуру Ленинградского научно-исследовательского нейрохирургического института. Высокопрофессиональный специалист, хирург от бога он обладал ювелирной точностью и филигранной техникой. В этом же году значительно улучшена помощь эндокринологическим больным [8].

В апреле 1965 года в жизни медицинской общественности области произошло знаменательное событие: проведен 1 съезд медицинских работников Адыгеи. На съезд прибыло 450 делегатов врачей и среднего медперсонала. Лучшие из лучших: 11 врачей, имеющих звание Заслуженный врач РСФСР, 76 врачей, награжденных значками «отличник здравоохранения». Съезд открыл заслуженный врач РСФСР А.Х. Бжассо. На съезде обсуждались вопросы организации качества и культуры медицинского обслуживания населения области [9].

Охрана здоровья детей, оказание им всех видов медицинских услуг всегда были в центре внимания Облздравотдела. Медицинская помощь детям осуществлялась детским отделением областной больницы, городской детской больницей, дву мя детскими поликлиниками в городе. Обеспокоенность вызывала высокая детская смертность, которая была обусловлена, главным образом, смертностью новорожденных и составляла $71,1 \%$ от общего числа умерших детей. Такое положение было вызвано неудовлетворительной организацией акушерско-гинекологической помощи женщинам в городе. Показатели акушерско-гинекологической службы по краю являлись наихудшими. Обеспеченность родильными койками была ниже нормативов и составляла 0,5 коек на 1000 чел. населения. Отсутствовали нормальные условия для ранней госпитализации женщин с патологией беременности. Вообще, в педиатрической службе рост кадров отставал от роста сети здравоохранения. В связи с этим оставались неукомплектованными педиатрические кадры города (по области не хватало 28 врачей, из них 17 Майкопе) [10]. Изменилась нозологическая структура детских болезней. Если накануне 70-х годов можно было с уверенностью сказать, что такие опасные болезни, как скарлатина, дифтерия, сыпной тиф побеждены, то теперь увеличился рост тяжелых форм воспаления легких, как осложнение после респираторных вирусных инфекций, ревматизма, связанного с аллергизацией организма. По-прежнему был высок уровень больных рахитом и дистрофией. Неудовлетворительна была организация медицинской помощи школьникам. Изменения в сложившейся негативной ситуации педиатрической службы начались с подготовки и укомплектования кадров. Предоставлялись льготы при поступлении в институт в форме бронирования мест для подготовки врачей-педиатров; 
развернулась работа по повышению квалификации и усовершенствования кадров указанного направления.

Одним из активно развивающихся направлений медицины в эти годы являлась организация медико-санитарного обслуживания рабочих промышленных предприятий. В городе работало 24 здравпункта, подростковый кабинет, 10 цеховых врачей, промышленный и пищевой отделы горсанэпидстанции. Кроме того, к промышленным предприятиям были прикреплены участковые врачи поликлиник. Руководителям указывалось на необходимость создания для работников нормальных условий труда и строго спрашивалось за нарушение правил производственной санитарии и техники безопасности. Ежегодное проведение медицинских осмотров рабочих, служащих, учащихся, обязательная флюорография, диспансеризация, анализ заболеваемости и временной нетрудоспособности рабочих и служащих стало плановым для лечебно-профилактических учреждений города. Идея приоритета сохранения здоровья стала принимать более практичные формы в отечественной медицине [11].

70-е годы начинаются напряженной эпидемической ситуацией как для областного здравоохранения, так и для здравоохранения всей страны. В южные области страны проникла холера Эль-Тор. Возникла угроза чрезвычайной ситуации. Холера относится к особо опасным, конвенционным болезням. В связи с неблагополучием по заболеваемости острыми кишечными инфекциями распоряжением Облисполкома 10 марта 1970 г. образуется областная чрезвычайная противоэпидемическая комиссия (Ч.П.К.), разработаны и утверждены планы мероприятий по предупреждению и распространению острых кишечных инфекций. Лечебные учреждения укомплектованы по форме 30. Проведены конференции и практические занятия [12]. Угроза холеры обострила и обнажила все проблемы санитарно- эпидемиологической службы. Не раз обсуждался вопрос высокого уровня заболеваемости дизентерией. И каждый раз решение этого вопроса упиралось в круг проблем: недостаточное обеспечение населения доброкачественной питьевой водой, неудовлетворительное санитарное состояние населенных мест, отсутствие канализации, переуплотнение в детских учреждениях и неудовлетворительное состояние общепита, но наиболее острая - отсутствие элементарных условий для оказания стационарной помощи инфекционным больным. Например, с января по 15 марта 1973 года зарегистрировано 352 случая острых кишечных заболеваний, из них 175 не были госпитализированы. Инфекционное отделение на 100 коек при городской больнице было размещено в старом неогороженном здании, расположенном в 5-ти метрах от административного корпуса, и не отвечало санитарно-гигиеническим требованиям. Больные постоянно нарушали режим и выходили из отделения. Само отделение не имело бокса санпропускника. Необходимо было в кратчайшие сроки (19731975 гг.) построить типовую инфекционную больницу на 250 коек. С учетом напряженной обстановки, сложившейся в санитарно-эпидемиологической службе, на пятой сессии Адыгейского областного совета депутатов трудящихся от 20 апреля 1972 г. Было принято решение «O мерах по дальнейшему улучшению санитарного состояния области», к исполнению которого Облздравотдел приступил немедленно [13].

В 70-е и 80-е годы основным направлением работы областного и городского отделов здравоохранения стало продолжение строительства объектов специализированной помощи, повышение качества и культуры обслуживания. В частности, качество медицинской помощи для людей с повреждениями опорно-двигательного аппарата имело большое социальное и народно-хозяйственное значение. Инвалидность в результате травм опорно-двигательного аппарата занимало 1-е место в структуре инвалидности. В городе отсутствовала организованная 
специализированная помощь этой категории больных. Лечебная помощь оказывалась хирургами общего профиля. Имелся травмпункт при 1-й городской поликлинике, которая работала в 2 смены. Позже, в 1977 г. травмпункт вынесли за территорию городской больницы, и он становится самостоятельным учреждением с более широкими возможностями по оказанию лечебной, реабилитационной помощи и консультированию больных [14]. В 1973 г. открылось травматологическое отделение городской больницы на 65 коек. Возглавил его хирург I категории В.Н. Гончаров. В отделении работали врачи-ординаторы I категории С.И. Гладков, Г.Г. Устинов. Одновременно в хирургическом отделении областной больницы открылось 10 специализированных травматологических коек. Проведение указанных организационных мероприятий позволило значительно улучшить помощь данной категории больных. Однако такое разобщение стационарной помощи приводило к конфликтам между двумя центрами, а также распылению специалистов и материальной базы. Необходимо было решать вопрос о сосредоточении травматологической помощи в одном месте. По мнению специалистов наиболее целесообразной была ее концентрация в областной больнице, где уже были размещены нейрохирургическое и стоматологическое отделение, что и было сделано в 1976 г. [15].

С января 1976 г. были развернуты ангиографические койки в хирургическом отделении городской больницы. Материальная база и коечная мощность за эти годы значительно выросла. Заведующим отделением был врач высшей категории, главный хирург города Бойчевский Дмитрий Васильевич. Весь штат врачей состоял из высокопрофессиональных специалистов: врач высшей категории М.Я. Сивкевич, врачи первой категории Э.Д. Винник, И.А. Паниковский, врачиангиографы Ю.Г. Садырин, Н.И. Чайка, что позволяло оказывать качественную хирургическую помощь. Открыты были также анестезиологическое отделение в городской больнице и отделение реанимации в областной больнице [16]. В 70-х гг. отмечается также рост больных сахарным диабетом. 15 эндокринологических коек, открытых в I-м терапевтическом отделении, не позволяли госпитализировать всех, нуждающихся в стационарной помощи. Городской эндокринолог Г.Н. Тугуз поставила вопрос о необходимости расширения и улучшения помощи больным сахарным диабетом [17].

Несмотря на значительные успехи в развитии здравоохранения, в области все еще оставались узкие места в системе оздоровительных мероприятий. Таковым являлась акушерско-гинекологическая помощь. О чем свидетельствуют показатели отчетности по данному направлению. В 1974 г. отказали 330 беременным женщинам в госпитализации. Увеличилось количество преждевременных родов с 4,9/100 чел. в 1973 г. до 5,5/100 чел. в 1974 г. Возросла заболеваемость новорожденных, ведушее место в этой статистике занимали недоношенные дети (из 133 детей заболевало 58). Это свидетельствовало о необходимости открытия отделения для выхаживания недоношенных и больных новорожденных. Для улучшения ситуации в службе, вся акушерско-гинекологическая помощь концентрировалась в городской больнице, коечная сеть увеличилась до 290 мест. Это позволило значительно увеличить госпитализацию, в частности работающих женщин. Службу возглавила заместитель главного врача Владимирова Бэлла Хасановна, женщина выдающихся деловых качеств [18].

Одним из важных документов, определивших направление развития здравоохранения в 70-е - 80-е годы, явилось постановление ЦК КПСС и Совета Министров СССР от 22.09.1977 г. № 370, а также приказ МЗ СССР от 31.10.1977 г. № 972 «О мерах по дальнейшему улучшению народного здравоохранения». Этот документ стал для областного и городского отделов здравоохранения программным, 
определившим направление дальнейшего совершенствования системы охраны здоровья населения. В соответствии с постановлением был разработан перспективный план развития здравоохранения на 1977-1985 гг. Уже в 1979 г. согласно плану была сдана в эксплуатацию инфекционная больница, 2-я женская консультация на 250 посещений, детская поликлиника, аптека, аптечный склад, взрослая поликлиника на 500 посещений в смену. Планировалось введение в строй нового роддома, а также трех профилакториев: для предприятия пищевой промышленности на 50 коек, для шпагатно-веревочной и канатной фабрики на 150 коек и для ЦКЗ на 100 коек. Медицинские учреждения пополнились новой медицинской аппаратурой и оборудованием, приобретенных как за счет бюджетных ассигнований, так и через шефские предприятия и организации [19].

Приход к власти М.С. Горбачева в 1985 году и провозглашение нового курса развития для партии и государства был встречен всем советским народом положительно. Страна как всегда доверяла и верила благостным намерениям партии. Областное здравоохранение вместе со всем обществом вступило в новый этап успешного выполнения и перевыполнения заданий XI-й пятилетки, стараясь понять и примериться к новым понятиям «перестройка», «гласность», «демократизация», не предполагая тех революционных потрясений, которые они принесут. Социально-экономические реформы, проводившиеся в стране, привели к изменению форм собственности, разрушению структуры финансирования, развалу экономики. Все это сопровождалось ростом безработицы, резким ухудшением уровня жизни - вплоть до обнищания населения. Шоковая терапия, сопровождавшая экономические реформы, стала стрессогенной для общества. Кривая заболеваемости и смертности резко пошла вверх, a рождаемости вниз.

Изменение форм и характера хозяйствования сопровождалось реорганизационными мероприятиями. В соответствии с решением облисполкома от 23.09.1988 г. № 259 отдел здравоохранения Облисполкома реорганизован в Управление здравоохранения Адыгоблисполкома. В 1992 году в связи с образованием Республики Адыгея на основании Указа Президента Республики Адыгея № 6 от 31.01.1992 г. Управление здравоохранения реорганизовано в Министерство здравоохранения Республики Адыгея, которое возглавил Мамгетов Касим Юсуфович [20].

Таким образом, представленный материал позволяет проследить развитие советского здравоохранения в Адыгее в послевоенный период. Несмотря на экономические сложности, советское государство уделяло большое внимание охране здоровья народа, считая её одной из важнейших социальных функций. Такая постановка проблемы на государственном уровне и высокая ответственность региональных властей при использовании государственных ассигнований позволили построить за годы советской власти эффективную систему медицинской службы в Адыгее.

\section{ЛИТЕРАТУРА:}

1. Государственное учреждение «Национальный архив Республики Адыгея» (ГУ НАРА) Ф.Р-79. Оп. 3 Д. 288. Л.30.

2. Закон СССР от 15.03.1946 «О преобразовании Совнаркомов в Совмины» // Сборник законов СССР и указов Президиума Верховного Совета СССР. 1938 г. - июль 1956 г. М., 1956. C. $77-78$.

3. ГУ НАРА. Ф. Р-79. ОП. 3. Д. 58. Л. 189.

4. Там же. Ф. Р-17. Оп.1. Д. 173. Л. 50.

5. Там же. Оп.1. Д. 234. Л. 35. 
6. Там же. Ф. Р-1. Оп. 1. Д. 14. Л. 21.

7. Там же. Ф. Р.17. Д. 30. Оп. 1. Л. 50.

8. Там же. Ф. Р-1. Оп. 3. Д. 74. Л. 13, 112.

9. Там же. Л. 114

10. Там же. Д. 548 . Л. 5, 16, 28, 37, 46, 47.

11. Там же. Ф. Р-17. Оп. 1. Д. 586. Л. 104.

12. Там же. Ф. Р-233. Оп. 2. Д. 354. Л. 58.

13. Там же. Ф. Р-1. Оп. 1. Д. 661. Л. 1.

14. Там же. Ф. Р-1 Д. 307. Л. 52, 92

15. Там же. Ф. Р-233. Оп. 2. Д. 498. Л.10.

16. Там же. Л.158, 219.

17. Там же. Ф. Р17. Оп.1. Д. 571. Л. 198.

18. Там же. Ф. Р-233. Оп. 2. Д. 490. Л. 65.

19. Там же. Оп. 1. Д. 505. Л. 1.

20. Там же. Ф. Р.17. Оп. 1. Титульный лист.

\section{REFERENCES:}

1. State institution «The National Archives of the Republic of Adygea» (SI NARA) F. R-79. Op. 3 D. 288 . L. 30.

2. Law of the USSR of $15 / 03 / 1946$ "On the transformation of Sovnarkoms into Sovmins» // Collection of laws of the USSR and decrees of the Presidium of the Supreme Soviet of the USSR. 1938 - July 1956 M., 1956. P. 77-78.

3. SI NARA. F. P-79. Op. 3. D. 58. L. 189.

4. Ibid. F. P-17. Op. 1. D. 173.L. 50.

5. Ibid. Op. 1. D. 234. L. 35.

6. Ibid. F. R-1. Op. 1. D. 14. L. 21

7. Ibid. F. R. 17. D. 30, item 1. L. 50.

8. Ibid. F. R-1. Op. 3. D. 74. L. 13, 112.

9. Ibid. L. 114.

10. Ibid. D. 548. L. 5, 16, 28, 37, 46, 47.

11. Ibid. F. P-17. Op. 1. D. 586. L. 104.

12. Ibid. F. R-233. Op. 2. D. 354 . L. 58.

13. Ibid. F. R-1. Op. 1. D. 661, Sheet 1.

14. Ibid. F. R-1 D. 307. L. 52, 92.

15. Ibid. F. P-233. Op. 2. D. 498. L. 10.

16. Ibid. L. 158, 219.

17. Ibid. F. R17. Op.1. D. 571. L. 198.

18. Ibid. F. P-233. Op. 2. D. 490. L. 65.

19. Ibid. Op. 1. D. 505. L. 1.

20. Ibid. F. R.17. Op. 1. Title page. 